\title{
Ethical Issues in Clinical Neuroscience Research: A Patient's Perspective
}

\author{
Perry D. Cohen, Linda Herman, Sheryl Jedlinski, Peggy Willocks, and Paula Wittekind
}

Parkinson Pipeline Project, Washington, DC

\begin{abstract}
Summary: A patient-centered paradigm for clinical research and medical care is presented as a solution to the problem of declining innovation and increasing costs and development time in the pipeline for new therapies. Fundamental differences in values and motivations among scientists, clinicians, industry sponsor, and patients in neurotherapeutics provide a framework for analysis of ethical conflicts and the loss of public confidence in medical research. Parkinson advocates' views on clinical trial participation, perceived risks and benefits, placebo controls, and sham surgery are presented. These views reflect the sense of urgency and the unique perspective that comes from living with this progressive, debilitating condition full time. A patient-centered paradigm that includes authentic voices of patients as collaborators at every stage of development will help to resolve conflicts, build trust, recruit trial participants, and accelerate new therapies. Key elements are
\end{abstract}

adaptive clinical trial methods and the development of information technology for the assessment of outcomes and surveillance of safety over the life cycle of a medical product. Supported by the Parkinson's Disease Foundation, the Parkinson Pipeline Project is a grassroots group of Parkinson's patients whose goal is to represent an authentic voice for patients in the treatment development process. This group promotes education and communication between members of the Parkinson's community and active stakeholders in medical research, industry, and regulatory agencies. Its members are an example of a new breed of knowledgeable consumers, armed with first-hand access to research findings and reinforced by on-line connections to like-minded peers throughout the world. Key Words: Parkinson's disease, sham surgery, placebo, ethics, conflict of interest, patient voice, patient-centered care.

\section{INTRODUCTION}

The current scientific model for therapy development is nearing a breaking point. Fewer innovative, new treatment applications and therapies are being submitted to the FDA, and costs, regulations, intellectual property issues, and shortages of other resources are rapidly increasing. ${ }^{1}$ We contend that now is the time to fundamentally reform the scientific model for evaluating new therapies by adding the human element - the unique patient perspective. Here the particular perspective is that of people with Parkinson's disease (PWP).

This vision of a patient-centered paradigm calls for greater collaboration with patients as full partners throughout the clinical trial process, and not only as volunteer research participants, but also as educated patient advocates at the table, where research policy decisions are determined. Engaging patients in collaboration and dialogue with clinical researchers will promote a

Address correspondence and reprint requests to: Perry D. Cohen, $\mathrm{PhD}$, Project Director, Parkinson Pipeline Project, 3914 Harrison St. NW, Washington DC 20015. E-mail: perry.cohen@sloan.mit.edu. better understanding of the differences between people and laboratory animals and the role of self-awareness, hopes, expectations, attitudes, and advocacy (self-help) in treatment. This will help build trust, recruit clinical trial participants, and promote more effective development of new therapies.

\section{CONFLICTING CORE VALUES POSE ETHICAL DILEMMAS}

Ethics in clinical research must reconcile conflicts in core values of the primary stakeholders in the process. Characterizations of the essential features of the values and motivation of each stakeholder group-scientists, clinical care providers, industry sponsor, and patientsillustrate the most fundamental value conflicts between groups.

Scientists are driven by their desire to advance knowledge and apply it to the development of improved medical treatments and devices. They prize the scientific method, which relies on objective documentation of behavior and outcomes, statistical analysis, hypothesis testing, and replication of results. They strive to avoid sta- 
tistical error and bias, which may result from patients' or providers' expectations.

Clinical care emphasizes the positive effects patients receive from medical interventions. Research pushes new knowledge to the forefront, directly addressing questions and needs relevant to daily clinical practice. However, the scope and success of new interventions may be limited by finite resources and by competition for the time of community healthcare providers to adopt evidence-based interventions at the practice level.

Once enrolled in a clinical trial, a volunteer becomes both a patient and a trial participant, and the doctor becomes both physician and researcher. This may lead to ethical conflicts, because medical research and medical care have differing objectives. Research is designed to answer a hypothetical question, but medical care is intended to provide treatment that is in the patient's best interest. Although most trials are not considered to be a form of therapy, investigators are still obligated to do more than just avoid exposing participants to excessive risks. The American Medical Association's (AMA) Code of Medical Ethics (as cited by Glass and Waring ${ }^{2}$ ) specifies that "investigators testing treatment efficacy must recognize the patient-physician relationship and exercise professional judgment and skill in the best interest of the patient."

A multistage preclinical and clinical regulatory process aims to protect patients' safety by gradually increasing their exposure to the risks of new medicine and rigorously evaluating outcomes at each stage. Performing these costly experiments to prove the safety and efficacy of a new medicine requires a highly capitalized pharmaceutical and medical products industry. In business, ethical behavior is derived from the ideals of competitive free-market economies. Exchanges between actors pursuing their own self-interests are governed by underlying economic forces of supply and demand. Although legal protections such as patent laws and large public subsidies have altered the free-market assumptions, industry continues to use these values to justify its actions.

Conflicting core values among key stakeholders in the clinical research process (scientists, clinical care providers, industry and sponsors, and patients) often pose ethical dilemmas. For example, the high value placed on clinical improvement by doctors and patients can be at odds with the scientific method, which looks for predetermined statistical differences between treatment and control groups. At the same time, the value science places on information-rich environments can be in conflict with the perceived needs of industry for proprietary information in a competitive marketplace.

\section{UNETHICAL BEHAVIOR ELICITS PUBLIC DISTRUST}

"Public distrust of clinical research is the result of lapses in integrity on the part of stakeholders on all sides of the debate-academia, medical journals, regulatory organizations, government agencies, industry, and other members of the research community," states Kenneth A. Getz, ${ }^{3}$ a senior research fellow at the Tufts Center for the Study of Drug Development. "None of these stakeholders are licensed to drive the debate alone. They must collectively address the rising level of public distrust with the benefit of input and insight from the public."

What is the source of this public distrust? What are the behaviors that appear to be unethical from a patient's perspective that might warrant the growing cynicism? As advocates, we have closely observed the process of transforming science into life-saving treatments. While we believe the vast majority of professionals involved in clinical neuroscience are ethical, we have also seen stark examples of activities conducted in the name of patient interests that appear to be done for self-interest, including financial gain, career advancement, or the attainment or protection of a position of influence in a profession or community. From a patient perspective, these basic human motivations are not necessarily unethical unless they are presented as being in a patient's interests when in fact they may not benefit patients and may even be detrimental to research participants or to general patient interests. A few examples include the following.

- A regulatory process that protects proprietary information and the competitive commercial interests of industry, even if it is not in the best interests of patients who want to apply science expeditiously to improve treatment.

- Scientists working with industry who have significant ownership or consulting activity and make judgments about study outcome efficacy or patient safety that may not be fully transparent, accurate, or in the best interests of research participants or patients in general.

- An industry that accepts the benefits of publicly funded research, but does not fulfill its public obligations to share results of studies or fulfill its commitments to patients, who accept huge risks by participating in medical experiments.

\section{WHAT PATIENTS WANT}

Patients volunteer for clinical trials for a myriad of reasons. The top two, according to a 2005 Harris Poll, ${ }^{4}$ are to advance science and medicine $(51 \%)$, and to obtain better treatment $(46 \%)$. The most common reasons given for considering participation in future trials are: "If I had a terminal illness" (71\%), "If I thought a drug might cure 
me" (67\%), and "If there were no other medical options available to me" $(66 \%)$.

The gold-standard treatment for Parkinson's disease, levodopa, is more than 40 years old and loses its efficacy as the disease progresses with disabling side effects. Is it any wonder why PWP with advancing disease feel a sense of urgency to get improved therapies on the market and into the clinic, and are frustrated by the slow drug approval process and the ethical conflicts that can further delay the process? Medical professionals may often mistake this urgency for desperation, but patients view themselves as informed and realistic.

In an April 2006 interview for NBC's "Dateline" program, Michael J. Fox ${ }^{5}$ described Parkinson's patients: “There's urgency but there's also strength ... not desperation. They're urgent ... adamant . . . committed, and they're hopeful."

Where certainty of disease progression is the baseline in any risk-benefit analysis, patients are more concerned about avoiding false negatives, or Type II errors, than about avoiding false positives (Type I errors). Type II errors may keep effective treatments off the market, but Type I errors may expose patients to high risks of side effects from treatments that offer no potential benefit. The latter violates the ethical core of all medicine: "Do no harm."

Well-informed patients living with chronic, debilitating conditions are willing to take risks because, as Linda Golodner, ${ }^{6}$ President of the National Consumers League, has said, "the greatest risk is a lack of new and improved treatment options."

Apart from a cure, what do patients want? Results of a 2004 National Institutes of Health Workshop, "Inviting Public Participation in Clinical Research: Building Trust through Partnerships," pants were determined to:

- Know the benefits/risks and relevance.

- Know their health and privacy are valued and safeguarded.

- Be treated as human beings.

- Be fully informed of researchers' conflicts of interest.

- Be advised of study results and post-study options for medical care.

- Receive interim information about study progress.

\section{PLACEBO EFFECTS AND SHAM CONTROLS}

\section{Scientists' Views}

Double-blind, placebo-controlled trials are considered to be the gold standard in clinical research. Many investigators cite the Freed $^{8}$ fetal cell tissue transplant study for advanced Parkinson's disease and subsequent fol- low-up studies by $\mathrm{McCrae}^{9}$ and others as evidence that the placebo effect may be especially strong and long lasting — as much as a year or more-in surgical treatments for Parkinson's patients.

In the initial study, human fetal cell tissue was implanted into the brains of patients in the treatment group; for the placebo group, burr holes were drilled in their skulls but nothing was implanted. Both groups were given anesthesia and intravenous antibiotics. Researchers argued that the risks associated with the surgery were reasonable in relation to the possible benefits from the outcome of the study.

Clinical researchers emphasize the importance of placebo-controlled trials, including sham surgeries, for evaluation of promising future treatments such as gene therapy and cell implantation. Of 103 investigator members of the Parkinson's Study Group ${ }^{10}$ who responded to an on-line survey in 2004, a vast majority believe that shamcontrol design is scientifically superior to an open control design and that it is ethically permissible. Specifically,

- $90 \%$ said drilling burr holes in the heads of shamcontrol group members is justified.

- $22 \%$ said penetration of brain tissue in a control group member is justified if it leads to a definite answer.

Even with this strong scientific consensus, the authors of this survey concluded that, to reach an informed ethical consensus about risks and benefits of sham surgery, policy judgments should involve multiple stakeholders, with potential research participants included.

\section{PATIENT ADVOCATE VIEWS}

Patient advocates ask how, in good conscience, we can sell our peers on placebo controls, and sham surgery in particular. The regulatory approval process does not require placebo-controlled trials. For example, DBS (deep brain stimulation) was approved by FDA with no placebo control. ${ }^{11}$

Previous studies citing observed improvements in PWP following sham surgery overlook the fact that this so-called placebo consisted of a range of interventions that put patients at significant risk. Sham surgery is not a sugar pill. Patients incur not only the risks of having a hole drilled in their heads, but also the significant risks associated with undergoing anesthesia, as well as the emotional trauma of preparing oneself for experimental brain surgery with no expectation that these interventions will ease their symptoms.

Increasing risk for trial participants is not ethically justified unless, before agreement to participate is secured, the supporting evidence is clearly spelled out as part of an informed consent process that weighs individual risk-benefit choices. In a patient-centered clinical 
trial system, the burden of proof is on the researcher to show that the value of the data to be gained from the placebo group outweighs the risks to the participant. A study would have to provide evidence for prolonged positive effects from the sham intervention and show a difference between this placebo surgery and other possible controls, such as no treatment groups or historical controls. $^{12}$

If there should be lasting placebo effects from sham surgery, patients might not consider these to be false positives. Similarly, our personal experiences in clinical trials highlight an artificial neutrality (apparently to avoid bias) implicitly or explicitly imposed on researchers. Neither this nor the elaborate deceptions acted out in double-blind studies reflect optimal patient-physician interactions.

Physicians should not be criticized for providing false hope or for being too close to their patients. There is nothing false about hope. Patients need hope to function in the face of the relentless 24/7 grind of Parkinson's disease and the daily medication roller-coaster ride. Hope and positive expectations are key elements of healing $^{13}$ that should be encouraged, and not written off as a placebo effect.

\section{Clinical Trial Participant Views}

Lynda McKenzie, of Ontario, Canada, participated in the embryonic tissue transplant study and was first among those given sham surgery. She experienced placebo effect-related improvements for only a few months, and then waited two years for a second brain surgery and the fetal cell implant. McKenzie says she is a "risk taker" and "likes to be on the cutting edge of research." Asked how she felt about sham surgery, she said, "I'd do it again because it gave me a few years of relief" (personal communication).

Peggy Willocks, of Tennessee, a research participant and a co-author of this article, sees it differently. She was one of the original six patients in the open-label Phase I, Spheramine retinal cell implant trials, in which all participants knew they were getting the implants. Willocks has said, "I'd have to think long and hard about going through the motions of having brain surgery and possibly not getting the treatment... that would seem emotionally and medically unethical."

According to one researcher, "There's literature representing the opinion of neurologists and ethicists but little to formally represent patient opinions. Before we inject the 'putative curative stuff,' we should assess patients' willingness to participate, knowing they may receive a potentially injurious agent."14

The lack of information regarding patient views could be due to the low number of neurological clinical trials conducted thus far involving sham surgery. Assessment of patient outcomes from sham surgery and alternative trial designs must be monitored and data shared in a timely fashion to determine the actual value of this practice. In the absence of such research, it is imperative that judgments about the ethics of this practice be discussed with patients at the table.

\section{ALTERNATIVE STUDY DESIGNS}

There are alternative study designs to large, costly hypothesis-testing clinical trials that more easily fit with the natural process of discovery. Adaptive trial designs and Bayesian methods use information and knowledge about gene and protein markers or patient characteristics to modify designs in an iterative process. These designs can reveal more about the safety and efficacy of drugs and other therapies in shorter time frames, while exposing fewer people to experimental treatments, and result in more efficient and attractive clinical trials to potential participants and their physicians. ${ }^{15}$ Adaptive clinical trial designs are particularly helpful in the discovery phases of new therapy development, where learning from early experience is incorporated into the design of subsequent steps, such as identification of 'responders,' and dose-finding studies for use in future efficacy studies.

Cross-over designs, where all patients get a real treatment after a period of comparison to placebo, are more justifiable than pure placebo control, which allows for no follow-up. As was true for DBS, an effect size large enough to warrant the risks of brain surgery $(25 \%$ improvement in motor symptoms) will be obvious even without statistical analysis. Given the alternatives, exposing patients to the risks of sham surgery in most cases is unethical and should be avoided.

\section{COMMUNICATION WITH RESEARCH PARTICIPANTS}

Another major issue for trial participants is the lack of procedures to facilitate communication with sponsors. This was painfully evident when Cephalon suddenly halted its safety and efficacy study of a potential neuroprotective agent (CEP1347) involving more than 800 untreated patients with early Parkinson's disease. Corporate stockholders were quickly notified of this as required by securities law that makes it a crime to withhold material information from those with financial interests in a public company. Clinical trial participants and study center staff learned about the halt from the business news media. They received no guidance as to the next steps, such as whether to stop taking the experimental drug immediately, titrate off of it, or stay the course until they were told otherwise. This created a fear of adverse effects among research participants and a concern about malpractice among ill-informed staff. 


\section{ETHICAL OBLIGATIONS FOR SPONSOR FOLLOW-UP}

Doctors may be able to convince their patients to agree to participate in clinical trials because the patients trust them and are persuaded to take a risk for the good of the community and the sake of scientific advancementparticularly for novel and potential breakthrough therapies. This positive motivation cannot be sustained over the longer run, however, unless sponsors' actions also demonstrate that they are aware of patient interests and the risks they have taken by making commitments for follow-up treatment that are commensurate with the extent of risk taken. The promised follow-up can only be guaranteed by extending the informed consent processes between patients and clinical researchers to include legally enforceable agreements between patients and sponsors.

When the U.S. District Court upheld Amgen's rights to halt the open label continuation promised to research participants in the Phase I and II clinical trials for GDNF, these patients learned, after the fact, that they had no rights to enforce that agreement and no legal relationship with the sponsor. Safety concerns from concurrent animal studies were cited as justification for the decision to halt GDNF development (even though the interpretations were not confirmed in a regulatory review of the data), and dramatic improvements in patients' symptoms in open-label studies were dismissed as placebo effect.

This decision remains highly controversial in the Parkinson's community, and in the meantime a continuing stream of peer-reviewed publications ${ }^{16-23}$ has raised questions about the validity of conclusions drawn from the available data. Not only has this treatment been withdrawn from research participants who would be willing to take the risk of continued exposure to GDNF with FDA concurrence, but also much valuable information on the long-term safety of a promising therapy has been lost, and the availability of a promising treatment for all PWP may have been delayed significantly. ${ }^{24}$ The company and its scientific supporters did not seek input from actual patients in making their decision, and explicitly excluded patients from the scientific meetings conducted to decide the fate of GDNF. In the absence of this patient perspective, issues of prime importance to patients were not raised-particularly the urgency felt by advancing patients to get improved therapies on the market sooner rather than later.

A Phase II GDNF trial participant, Chicagoan Steve Kaufman, experienced profound and long-lasting improvements of symptoms after only nine months on GDNF: "In September 2004, about a week before Amgen halted the trial, my wife told me she was starting to forget that I am sick. (Now) my pain is starting to gradually intensify again, so I know my body needs the medication. I don't want to go back to being the person I was every day before GDNF ... sitting in a chair, shaking, rigid, in pain, and antisocial. GDNF is to Parkinson's patients what insulin is to people with diabetes. I will not survive without it. Is anyone listening? Does anyone care?" (personal communication).

"We need to find better ways of balancing the interests and responsibilities of all stakeholders while maintaining focus on a shared goal of moving therapies forward and finding cures," said Robin Elliott, ${ }^{25}$ Executive Director of the Parkinson's Disease Foundation. "A critical piece of this is ensuring that patients' expectations and rights are fully incorporated throughout the entire clinical trial process."

\section{PATIENT ADVOCACY}

Rebecca Dresser, a member of the President's Council on Bioethics, says, "Bioethics is predicated on the premise that public and patient values matter-that physicians, scientists, and government officials should not hold complete control as to how medicine and research are practiced. Patient advocates brought to medicine and research the public participation that the bioethics community had been endorsing." 26

\section{Parkinson Pipeline Project}

The Parkinson Pipeline Project (see http://www. pdpipeline.org) is a grassroots working group of Parkinson's patients, affiliated with the Parkinson's Disease Foundation, whose slogan is, "The missing ingredient in the development of new therapies is the voice of the patient." Supported by the Parkinson's Disease Foundation, this group advocates for

- Inclusion of patients' perspectives in planning and conducting clinical evaluations of new therapies and diagnostics.

- Development of policies and practices that accelerate treatment approvals.

- Access to experimental treatments for seriously ill patients.

- Full disclosure of and access to research details and results.

- Full disclosure of conflicts of interest among the research team.

- Opportunities to educate trial participants, investigative staff, and treatment sponsors.

Experience with the ethical conflicts inherent in the development of new therapies has prompted the initiation of a "Research Participant's Bill of Rights and Responsibilities." This is to be used as a framework for promoting mutual trust, collaboration, and improved 
communication among patient advocates, clinical researchers, and sponsors of new therapies.

\section{A Voice at the Table}

The many talented PWP who have retired on disability at the peaks of their careers from a variety of technical, scientific, education, and business fields offer an untapped resource to help speed promising therapies through the pipeline. The Parkinson Pipeline Project empowers grassroots patient advocates to reach out, in order to:

- Educate patients about the requirements of new therapy development and the need for research participants, and

- Educate all stakeholders about the needs of patients and the contributions they can make to the research process and outcomes.

Pipeliners already have demonstrated effectiveness in counseling and providing outreach and communication within the Parkinson's community and in collaboration with the FDA, industry sponsors, and clinical research centers on research and regulatory issues.

The Pipeline Project's launch of a powerful, interactive treatment database provides advocates with intelligence about the status of the current pipelines for development of new Parkinson's therapies, and gives the public and all other stakeholders easy, on-line access to reliable and up-to-date information about therapies in the pipeline and clinical trials for Parkinson's disease.

Learning about future treatment options that can be discussed with their physicians can provide hope to all patients. Similar to the way that exercise is thought to improve motor problems with Parkinson's, hope may address emotional and spiritual issues. Patients who become active in advocacy learn and stay informed about the clinical trial processes and take positive action to improve outcomes. Patients find this advocacy to be an antidote to depression, apathy, and other psychological symptoms common in Parkinson's.

\section{HISTORIC ROUND TABLE BRINGS TOGETHER LEADING STAKEHOLDERS IN THE PARKINSON'S COMMUNITY}

To further improve clinical research and accelerate the development of Parkinson's therapies, the Parkinson's Disease Foundation (PDF) and the Parkinson Pipeline Project brought together leading stakeholders in the extended Parkinson's community for a full day round table on January 24, 2007. The ideas generated by this historic discussion provide the basis for:

- Recognizing that patient advocates as well as research participants are essential collaborators in the process of developing new therapies as authentic voices for PWP in the clinical trial process.
- Establishing expectations for productive stakeholder collaboration and calling for transparency in the sharing of information.

- Setting the stage for increased outreach, dialogue, and education throughout the Parkinson's community.

- Addressing key barriers to clinical trial participation and related deterrents to development of new therapies in a way that advances treatments and step by step brings us closer to cures.

- Developing a document outlining a Research Participant's Bill of Rights and Responsibilities, as guidelines for all participants on the informed consent processes in relation to both researchers and sponsors.

The round table is exactly what was called for in a December 2005 editorial in The Lancet Neurology: "The GDNF dispute illustrates the urgent need for pharmaceutical companies, clinical researchers and patients to join forces in modifying medical research in which study participants are commonly treated as passive subjects, have no control of the research process, and are often misled by the expectation of a therapeutic outcome."27

\section{PWP TAKE MORE ACTIVE ROLES IN CLINICAL RESEARCH}

Clinical research and medical care are predicated on the premise that the welfare of patients is the top priority. Scientists and clinicians, as well as insurers and manufacturers of medical products (medicines and devices), agree that the patient is the ultimate customer. The irony is that patients rarely have had a role in medical research beyond being the passive recipient of medical interventions-but this is changing.

After nearly three years in the proposal stage and two more in recruitment, training, and launching the program, Parkinson's patient advocates are now active consultants to FDA reviewers at the pre-approval stages of drug development, when industry sponsors and researchers present their study protocols and analyses of the phase data. This gives PWP a seat at the table (the first, for any neurological condition) where decisions are made to affect outcomes and help regain lagging momentum in realizing the scientific promise of new therapies. Many PWP are available who have the background to understand the technical and scientific discussions, as well as having firsthand experience as participants in clinical studies to make important contributions from the patient perspective.

Other important trends toward patient-centered clinical research and health care include the adaptive trial designs already mentioned, to adjust designs and research targets based on information in prior steps in a 
more continuous learning process extending beyond the formal regulatory approval to the life cycle of the treatment.

A central theme of user-fee legislation (PDUFA IV) being discussed in the U.S. Congress in 2007 is the great need for post-market surveillance to monitor the safety of therapies when they are applied to wider populations over longer time periods. Data would initially be obtained from large managed care health plans and other third party payers. Over time, data collection would be integrated into the practice of medicine using electronic medical records and personal health records to compile databases and act as local registries for specific diseases. Combined with other data on cost, utilization, and outcomes of care, these data provide the information needed for competition over delivery of the highest value and quality medicine in a patient-centered system. In this context, regulators could provide earlier conditional approvals for new treatments for serious illnesses, thus vastly reduce the time and cost of development and still maintain close control of safety problems. ${ }^{28}$

\section{CONCLUSION}

Here we have provided examples of the human element in clinical trials and illustrated the need for authentic voices of patients in the development of new therapies. Well-educated, highly motivated patient advocates provide for a patient voice that becomes authenticated when it is accepted and respected as an integral part of all facets of the drug approval process. Participation of patients in the development and approval of new therapies will lead to greater appreciation by scientists, regulators, and sponsors of our urgent needs for more effective therapies. We must shed business as usual, science as usual, and politics as usual and advocate for faster cures-safely and expeditiously-from the patient perspective.

Acknowledgments: The work of the Parkinson Pipeline Project is supported by volunteer efforts of people with Parkinson's and receives administrative and financial support from the Parkinson's Disease Foundation.

\section{REFERENCES}

1. United States Government Accounting Office. New drug development: science, business, regulatory and intellectual property issues cited as hampering drug development efforts. GAO-07-49, a report to congressional requesters. November 2006. Available at: http:// www.gao.gov/new.items/d0749.pdf. Accessed January 20, 2007.

2. Glass KC, Waring D. The physician/investigator's obligation to patients participating in research: the case of placebo controlled trials. J Law Med Ethics 2005;33:575-585.

3. Getz, KA. Forgotten voices in the transparency debate: online trial registries alone will not succeed at rebuilding public confidence. Appl Clin Trials 2006 April. Available at: http://www. actmagazine.com/appliedclinicaltrials/article/articleDetail.jsp?id= 316473. Accessed May 22, 2007.
4. Gullo, K. New survey shows public perception of opportunity to participate in clinical trials has decreased slightly from last year. Harris Interactive Healthcare News 2005;5(6):1-14. Available at: http://www.harrisinteractive.com/news/newsletters/healthnews/ HI_HealthCareNews2005Vol5_lss06.pdf.

5. Fox, M. Michael's mission [Dateline Interview with Katie Couric]. April 16, 2006. Available at: http://www.michaeljfox. org/newsEvents_michaelInTheNews_article.cfm?ID $=28 . \quad$ Accessed January 20, 2007.

6. National Consumers League. Survey: Public believes decisions concerning treatment should rest with patients and physicians. NCL News: Releases \& Advisories. March 6, 2006. Available at: http://www.nclnet.org/news/2006/chronic_disease_survey_03062006. htm. Accessed January 20, 2007.

7. Workshop proceedings-Inviting public participation in clinical research: building trust through partnerships. October 26-27, 2004. A workshop sponsored by the National Institutes of Health Director's Council of Public Representatives (COPR); coordinated in partnership with the NIH Public Trust Initiative. Available at: http://copr.nih.gov/reports/October_2004_COPR_WORKSHOP_ Proceedings.pdf. Accessed January 20, 2007.

8. Freed CR, Greene P, Breeze R, Tsai WY, DuMouchel W, Kao R, et al. Transplantation of embryonic dopamine neurons for severe Parkinson's disease. N Engl J Med 2001;344:710-719.

9. McRae C, Cherin E, Yamazaki TG, et al. Effects of perceived treatment on quality of life and medical outcomes in a double-blind placebo surgery trial. Arch Gen Psychiatry 2004;61:412-420.

10. Kim SY, Frank S, Holloway R, Zimmerman C, Wilson R, Kieburtz $\mathrm{K}$. Science and ethics of sham surgery: a survey of Parkinson disease clinical researchers. Arch Neurol 2005;62:1357-1360.

11. U.S. Food and Drug Administration, Department of Health and Human Services. FDA approves implanted brain stimulator to control tremors. Released August 4, 1997. p97-24. Available at: http://www.fda.gov/bbs/topics/NEWS/NEW00580.html.

12. Polgar S, Ng J. Ethics, methodology, and the use of placebo controls in surgical trials. Brain Res Bull 2005;67:290-297.

13. Havemann J. The best medicine may be hope. The Hamilton [Ontario] Spectator; November 29, 2006; A.7. Available at: http:// www.grassrootsconnection.com/HaveHope.htm.

14. Frank S, Kieburtz K, Holloway R, Kim SYH. Author reply [to W Landau comment on: What is the risk of sham surgery in Parkinson disease clinical trials? A review of published reports. Neurology 2005;65:1101-1103]. Neurology 2006;66:1788-1789.

15. Berry D. A guide to drug discovery: Bayesian clinical trials. Nat Rev Drug Discov 2006;5:27-36.

16. Chebrolu H, Slevin JT, Gash DA, et al. MRI volumetric and intensity analysis of the cerebellum in Parkinson's disease patients infused with glial-derived neurotrophic factor (GDNF). Exp Neurol 2006;198:450-456.

17. Hutchinson M, Gurney S, Newson R. GDNF in Parkinson disease: an object lesson in the tyranny of type II. J Neurosci Methods 2006(Jul 27) [Epub ahead of print].

18. Lang AE, Gill S, Patel NK, et al. Randomized controlled trial of intraputamenal glial cell line-derived neurotrophic factor infusion in Parkinson disease. Ann Neurol 2006;59:459-466 [Erratum in: Ann Neurol 2006;60:747].

19. Love S, Plaha P, Patel NK, Hotton G, Brooks DJ, Gill SS. Glial cell line-derived neurotrophic factor induces neuronal sprouting in human brain. Nat Med 2005;11:703-704.

20. Patel NK, Bunnage M, Plaha P, Svendsen CN, Heywood P, Gill SS. Intraputamenal infusion of glial cell line-derived neurotrophic factor in PD: a two-year outcome study. Ann Neurol 2005:57:298-302.

21. Penn RD, Dalvi A, Slevin J, et al. GDNF in treatment of Parkinson's disease: response to editorial. Lancet Neurol 2006;5:202-203.

22. Salvatore M, Ai Y, Fischer B, et al. Point source concentration of GDNF may explain failure of phase II clinical trial. Exp Neurol 2006;202:497-505.

23. Slevin JT, Gash DM, Smith CD, et al. Unilateral intraputamenal glial cell line-derived neurotrophic factor in patients with Parkinson disease: response to 1 year of treatment and 1 year of withdrawal. J Neurosurg 2007;106:614-620. 
24. Fahn S, Elliott RA. PDF statement on Amgen's decision to block reinstatement of experimental Parkinson's treatment for trial participants. Released February 11, 2005. Available at http://www.pdf.org/ Publications/Amgens_Denial_Access.pdf. Accessed March 27, 2007.

25. Parkinson's Disease Foundation. Parkinson's Disease Foundation expresses concern at statement on Kentucky court decision supporting Amgen's denial of patient access to GDNF. Released July 12, 2005. Available at http://www.pdf.org/Publications/Amgens_ Denial_Access.pdf. Accessed March 27, 2007.
26. Dresser R. Patient advocates in research: new possibilities, new problems. Wash Univ J Law Policy 2003;11:237-248.

27. The hard way to a Bill of Rights [Editorial]. Lancet Neurol 2005; 4:787.

28. Gliklich R. Postapproval needs reassessed: real-world data demands place Phase IV studies in spotlight. Appl Clin Trials 2007 March. Available at http://www.actmagazine.com/ appliedclinicaltrials/article/articleDetail.jsp?id=410610. Accessed March 27, 2007. 